\title{
O PROBLEMA DA ORDEM
}

\author{
Rui Pena Pires
}

Instituto Universitário de Lisboa (ISCTE-IUL), CIES-IUL, Lisboa, Portugal

Falar de sociedade é o mesmo que falar de padrões nas relações sociais e nos comportamentos humanos. Ou seja, quando se admite que há algo a que chamamos sociedade é porque se admite que a vida social não é caótica mas ordenada, que existem regularidades nos comportamentos e nas interações observáveis, que as reações de outros aos nossos atos são em geral previsíveis. Por outras palavras, $r e-$ conhecemos a sociedade na ordenação da vida humana.

Se pensarmos um pouco, aquela ordenação constitui um enigma. As sociedades humanas são compostas por indivíduos que têm como propriedades específicas a autonomia, a criatividade, o livre-arbítrio. São esses indivíduos que nos seus atos e relacionamentos constituem sociedade. Pergunta: como se explica a emergência de padrões ordenados de atos e relacionamentos protagonizados por indivíduos autónomos, criativos e livres? E, segunda pergunta, que consequências têm sobre esses indivíduos aqueles padrões de atos e relacionamentos que se constituem, por sua vez, em contextos e meios da sua atividade? A resposta a estas questões, que podemos resumir como o "problema da ordem", constitui um dos objetivos nucleares da sociologia, em particular da teoria sociológica geral, qualquer que seja a tradição teórica considerada (Pires, 2007: 15).

A utilização da expressão "ordem social" para referir o objeto da sociologia gera frequentemente três tipos de objeções que assentam em equívocos fáceis de esclarecer. São eles os equívocos da reprodução, do consenso e do determinismo.

Em primeiro lugar, o centramento no problema da ordem não é sinónimo de atribuição de prioridade ao estudo da reprodução sobre o estudo da mudança social. Por um lado, porque a mudança não é a passagem da ordem ao caos, mas a substituição de um sistema de ordem por outro sistema de ordem. Por outro, porque é possível identificar, nos próprios processos de mudança, padrões (isto é, processos ordenados) de transformação, os quais devem ser analisados e explicados.

Em segundo lugar, valorizar o estudo da ordem não significa valorizar o consenso social em detrimento do conflito. Antes de mais, porque só é possível analisar e explicar os conflitos por referência às características da ordem social que naqueles processos são objeto de contestação. Depois, porque os conflitos não só são eles próprios processos ordenados, isto é, com propriedades gerais identificáveis, como induzem dinâmicas de organização intensas em cada uma das partes em oposição. Por fim, porque a definição de ordem como o oposto de caos, em termos estritamente factuais, não requer a ideia de consenso. A ordem tanto pode ser estável como instável, baseada na cooperação como na dominação e no conformismo, na responsabilidade moral como no interesse instrumental, no consenso como no confronto regulado, na semelhança como na variedade. Identificar e explicar os fundamentos e dinâmicas da ordem constitui, exatamente, um dos objetivos da 
teoria e da investigação sociológicas, não um ponto de partida destas. Essa explicação ganhará em ser multidimensional, no sentido em que será mais robusta se combinar "o destaque hobessiano da força, o pressuposto lockeano da complementaridade individual dos interesses e a enfatização, por Durkheim e Parsons, dos valores comuns" (Wrong, 1994:34), bem como, convirá acrescentar, os condicionamentos estruturais da ação.

Em terceiro lugar, centrar a análise e explicação sociológicas no problema da ordem não é o resultado de uma conceção determinista sobre a vida social, em que se anularia o reconhecimento da autonomia, criatividade e liberdade dos agentes humanos, em resumo, da "independência do indivíduo". Por um lado, porque, como se disse, "é a independência do indivíduo que torna a 'ordem' problemática" (Alexander, 1987: 12). Por outro, porque, como se procurará demonstrar, a independência do indivíduo depende, para ser efetiva, da existência de ordem, não de caos.

\section{Livre-arbítrio e previsibilidade}

A independência do indivíduo não é apenas uma propriedade subjetiva dos agentes humanos. É uma propriedade objetiva, isto é, que se exprime em atos. De facto, todo o indivíduo pode, em qualquer momento, agir (e não apenas pensar) em termos novos ou não esperados pelos outros. Só que, no que ao problema da ordem diz respeito, essa atuação é irrelevante se não tiver consequências sobre terceiros. E, do ponto de vista de cada indivíduo, essas consequências serão irrelevantes, ou mesmo indesejáveis, se não forem por ele minimamente previsíveis. Por outras palavras, "não é possível ser-se um agente efetivo se a ação não produz consequências previsíveis" (Burns e Dietz, 1992: 274).

A possibilidade de fazer a diferença no mundo em que se vive constitui a primeira e mais radical manifestação do problema da independência do indivíduo (designada por vezes como a questão da agência). Porém, a possibilidade de alguém agir de modo independente, com consequências prolongadas no tempo e alargadas no espaço, requer o controlo da reação dos outros a essa atuação independente. Ou seja, a independência dos atos de uma pessoa só é efetiva se os atos dos outros dependerem dos atos dessa pessoa, pelo menos em parte. Requer, por isso, o acionamento de mecanismos de construção da ordem, como o poder e a organização, acionamento esse condicionado pelo acesso a recursos sociais distribuídos de modo previamente ordenado. O que significa que a ordem é simultaneamente condição da ação independente (padrões de acesso aos recursos) e um dos seus resultados, sempre que essa ação independente é efetiva, isto é, sempre que tem consequências.

Fazer a diferença não através do controlo de outros mas do seu convencimento também requer e produz ordem. Se, por exemplo, alguém quiser ser criativo e influente no plano discursivo, terá de ser eficaz comunicacionalmente, o que significa recorrer a símbolos e códigos partilhados (ordem como requisito) e tornar compreensíveis, e portanto partilháveis, os resultados das inovações comunicacionais que operar sobre aqueles símbolos e códigos (ordem como resultado). 
Estes exemplos simples mostram que a hipótese da radical imprevisibilidade resultante da independência do indivíduo não tem em conta o caráter relacional da vida social, pois mesmo que fosse possível demonstrar "a existência de imprevisibilidade no comportamento de cada indivíduo humano, isso não significaria que a coincidência de comportamentos entre dois ou mais desses indivíduos fosse também imprevisível" (Wallace, 1983: 490). Se tivermos em conta, desde o início, que os atos individuais socialmente relevantes ocorrem, sempre, num quadro relacional, isto é social, serão claras e compreensíveis as relações entre atos criativos e inovadores, por um lado, e ordem social, por outro.

Dando atenção àquele quadro relacional, é ainda possível qualificar sociologicamente o problema da imprevisibilidade. De facto, num quadro relacional a relação entre livre-arbítrio e imprevisibilidade deve ser analisada não enquanto propriedade geral da ação humana mas como propriedade variável e probabilística de atos concretos. Ou seja, deve ser transformada na análise sociológica da incerteza que caracteriza a reação de outros aos atos de um agente. Vejamos alguns exemplos simples para esclarecer o significado destas afirmações e introduzir os principais argumentos necessários à sua sustentação.

Primeiro exemplo. Se, na compra de um bem ou serviço, alguém usar como meio de pagamento uma nota de valor superior ao desse bem ou serviço, não só pode prever que vai receber troco como o montante desse troco. Situação banal, dir-se-á, mas a maior parte da nossa vida quotidiana é feita de situações banais deste tipo.

Em rigor, porém, as previsões sobre o troco podem não se verificar, pois quem vende pode enganar-se nas contas ou tentar enganar quem compra. Erro e logro são sempre prováveis, embora de modo variável. Essa variação depende sobretudo da competência (no caso do erro) e da normatividade (no caso do logro) presentes na troca. É-nos possível medi-la com objetividade em termos estatísticos, enquanto sociólogos, e avaliá-la subjetivamente com base na experiência repetida da troca, enquanto atores sociais. Mais, dessa avaliação subjetiva poderá resultar a emergência de maior confiança em algumas das trocas, e portanto menor controlo do troco nessas trocas, bem como de menor confiança noutras trocas, e portanto de maior controlo do troco nesses casos.

Para analisar esta situação simples, seria possível construir um modelo elementar, e ainda incompleto, em que a previsibilidade no ato do troco fosse uma variável dependente associada, por exemplo, às seguintes variáveis independentes: (i) competência de cálculo de quem dá o troco; (ii) modo de cálculo do troco (manual, automático); (iii) compromisso moral de quem dá o troco; (iv) possibilidade de controlo do troco por parte de quem o recebe; $\mathrm{e}(\mathrm{v})$ probabilidade de sanção externa do erro e do logro (organizacional, jurídica, ...).

Neste modelo, a previsibilidade é probabilística e varia sobretudo em função de fatores sociais. Mesmo as duas variáveis aparentemente imputáveis às características de quem dá o troco (competência e compromisso moral) só têm efeitos se a probabilidade de sanção do erro e do logro for baixa. O que, por sua vez, significa que, em rigor, a probabilidade de incumprimento das expectativas de troco, numa troca, é menor em termos objetivos do que em termos subjetivos. 
Explicando melhor. A ocorrência de logro no troco não depende exclusivamente da vontade de quem queira enganar, mas também do grau de controlo e sanção do logro, ou seja, do caráter relacional do ato do troco. Mesmo admitindo que a vontade subjetiva possa ser mais ou menos indeterminada (o que não é totalmente correto), o controlo, a sanção e os seus resultados são processos objetivos que podem ser previstos em termos probabilísticos.

Em parte, essa maior possibilidade de previsão resulta da própria avaliação subjetiva que os atores envolvidos nas trocas fazem da confiança que podem depositar uns nos outros. Como se disse, quando a confiança falha começam por ser os próprios interessados na previsibilidade do troco a adequar o seu comportamento, dando uma maior atenção ao resultado do cálculo. Isto é, a previsibilidade é um objetivo valorizado nos relacionamentos, uma propriedade da vida social.

Consideremos ainda, para concluir este primeiro exemplo, situações em que a possibilidade de previsão prática do troco pode ser afetada por outras variáveis para além das já referidas. Quando alguém em viagem faz uma compra num país com outra moeda, o controlo do troco por quem o recebe requer o cálculo do câmbio e o conhecimento das notas e moedas usadas na transação. Quem recebe o troco tem menos controlo sobre o ato, podendo por isso ser mais facilmente enganado, a não ser que tente reajustar o seu comportamento demorando mais tempo a conferir o valor recebido. Reajustamento que poderá ser prejudicado pela reação de outros clientes que condenarão o atraso no atendimento que daí resulta para eles.

Ou seja, é possível prever que a imprevisibilidade relativa do troco aumenta quando quem compra não está familiarizado com a moeda usada na troca. Sobretudo, é possível prever que a perceção dessa imprevisibilidade relativa aumente devido ao menor controlo da situação por parte de quem compra, perceção essa geradora de insegurança nas transações em causa.

Duas conclusões podem ser retiradas desta segunda parte deste exemplo. Em primeiro lugar, o aprofundamento da construção da previsibilidade como variável social por identificação de mais fatores sociais que explicam essa variação. Em segundo, o reconhecimento de que a previsibilidade dos relacionamentos sociais é uma propriedade positivamente valorizada por quem neles se envolve. O que significa que a vida social é em geral previsível porque os agentes humanos procuram, com os seus atos, garantir tanto quanto possível essa previsibilidade nas relações em que participam. O que, por sua vez, tem como corolário que a incapacidade para garantir socialmente um mínimo de previsibilidade em certas relações sociais terá como consequência provável o progressivo abandono da participação nessas relações por um número crescente de indivíduos, sempre que possível, e, consequentemente, o eventual colapso dessas relações.

Segundo exemplo. No dia a dia da vida de uma organização, é elevado o grau de previsibilidade das atividades dos indivíduos nelas envolvidos. As organizações podem mesmo ser definidas como ambientes intencionalmente concebidos e desenvolvidos para garantir a previsibilidade da ação dos seus membros enquanto membros da organização. É essa previsibilidade que permite o funcionamento rotineiro de ambientes de risco elevado mas controlados organizacionalmente, como, por exemplo, um grande aeroporto. 
Aquela eficácia das organizações deve-se a um vasto conjunto de mecanismos relacionais: divisão do trabalho, sistemas de regras, modos de supervisão, incentivos e sanções, regimes de autoridade, etc. Neste artigo, importa apenas reter o último dos mecanismos referidos, os regimes de autoridade. Esses regimes concretizam o caráter hierárquico das organizações, que garante, em última instância, a estabilidade dos outros mecanismos identificados.

Porém, a relação entre hierarquia e previsibilidade comporta assimetrias. Por um lado, a hierarquização é um modo de controlo, e portanto de incremento da previsibilidade, de cima para baixo. Por outro, e pelo mesmo mecanismo, aumenta a imprevisibilidade de baixo para cima, isto é, aumenta a probabilidade de tomada de decisões pelos superiores não previsíveis pelos subordinados.

O que está em causa neste exemplo é a variação hierárquica do arbítrio. Enquanto ato e não apenas vontade, este é, numa organização, menos uma propriedade de quem decide e mais uma propriedade do lugar de decisão. Noutros termos, a imprevisibilidade do arbítrio varia em função do lugar nas hierarquias sociais, diminuindo de cima para baixo e aumentando de baixo para cima. Varia, em resumo, e uma vez mais, em termos relacionais.

Terceiro exemplo. Nas sociedades modernas tende a predominar um modelo de conjugalidade baseado no princípio da liberdade de escolha do conjuge. Em consequência, existe sempre um elemento de incerteza numa proposta de namoro ou casamento, não sendo possível eliminar a possibilidade de resposta indesejada. Ou seja, o caráter livre da escolha aumenta a imprevisibilidade da resposta.

Este exemplo coloca duas novas questões. Primeira, a previsibilidade de um ato afetivamente neutro, por exemplo um ato profissional, pode ser maior do que a previsibilidade de um ato afetivo. Segunda, um mesmo ato (uma proposta de namoro ou casamento) pode ser afetivamente neutro ou afetivo em função da sua diferente definição cultural em diferentes sociedades. Num casamento negociado pelos pais ou outros familiares tendem a predominar considerações instrumentais sobre considerações afetivas. Uma vez mais, a previsibilidade da ação é socialmente variável, neste caso em função do tipo de ato em causa e da definição cultural desse ato.

Resumindo os argumentos desta secção:

a) não é logicamente possível compatibilizar a ideia de independência do indivíduo com a de imprevisibilidade dos seus atos independentes, pois a agência só é efetiva quando produz consequências previsíveis;

b) o facto de o comportamento de cada indivíduo poder ser imprevisível não significa que as relações entre os indivíduos sejam, por isso, também imprevisíveis;

c) num quadro relacional, isto é social, a imprevisibilidade dos atos individuais deve deixar de ser analisada enquanto atributo geral da ação humana e passar a ser estudada como propriedade variável e probabilística de atos concretos;

d) o grau de previsibilidade dos atos individuais depende do tipo de ato, do tipo de ator e do contexto relacional e cultural do ato; 
e) a previsibilidade do comportamento humano é uma propriedade positivamente valorizada e ativamente promovida pelos indivíduos nas relações sociais em que participam.

A última alínea pode ser desdobrada em duas, em função do domínio da ação em causa:

e1) no domínio da ação estratégica, a eficácia depende do controlo do arbítrio de outros, o que, quando conseguido, tem efeitos de ordenação das relações sociais;

e2) no domínio da ação quotidiana, a procura de segurança relacional obriga a esforços de redução da incerteza na resposta de outros (reforço da previsibilidade), o que, quando conseguido, tem efeitos de ordenação das relações sociais.

Em conjunto, estes desdobramentos indicam, por um lado, que a previsibilidade é uma das características, variáveis, da ordem social, por outro, que a ordem é uma condição de eficácia da ação. Estas são duas propriedades fundamentais da vida social.

\section{Reflexividade e regularidades}

A autonomia, criatividade e liberdade dos agentes humanos não constituem pois manifestações duma oposição lógica e empírica entre indivíduo e sociedade. Entre estes termos está em causa, mais do que oposição, um modo de relacionamento que, entre outras propriedades, se caracteriza pela reflexividade. Isto é, os agentes humanos são competentes para analisar os contextos da ação e para, na sequência da análise, alterar esses contextos. Mais precisamente, a reflexividade significa que, em abstrato, os agentes humanos (i) são competentes para analisar os contextos em que atuam, (ii) são competentes para, nesses contextos, monitorar os seus atos e os resultados destes, (iii) são capazes de ajustar o comportamento em função daquela monitorização e (iv) são capazes de alterar os contextos na sequência da análise e monitorização efetuadas.

Em termos analíticos, cada um destes enunciados precisa de ser transformado em variável a partir de uma qualificação extra do tipo "ainda que de forma limitada e desigual, a qual depende de...". Porém, para o argumento desta secção interessa-nos apenas reter a conclusão geral que deles se pode retirar, a saber, que no decurso da ação o conhecimento sobre a ação e sobre o contexto permitem alterar tanto a ação como o contexto.

$\mathrm{O}$ conhecimento em causa pode ser de três tipos. Em primeiro lugar, o conhecimento prático dos agentes humanos sobre os contextos da ação. Em segundo lugar, o conhecimento analítico dos agentes que ocupam posições hierárquicas de desempenho estratégico. Finalmente, o conhecimento científico e técnico dos peritos. 
No primeiro tipo está em causa a especificação do mecanismo que permite reações adaptativas dos agentes a ambientes que, mesmo quando conhecidos, apresentam variações que requerem interpretação para uma ação competente. No segundo e terceiro tipos estão em causa modos de conhecimento que envolvem ou podem envolver uma relação de maior complexidade entre conhecimento e objeto do conhecimento. Nestes casos, de reflexividade alargada, o conhecimento sustenta não apenas reações adaptativas mas também criativas, o conhecimento muda o que é conhecido. No limite, "o conhecimento reflexivamente aplicado às condições de reprodução do sistema [social] altera intrinsecamente as circunstâncias a que originalmente se reportava" (Giddens, 1992 [1989]: 42).

O reconhecimento desta relação entre conhecimento e objeto, designada como dupla hermenêutica, tem suscitado questões sobre a estabilidade da ordem social, isto é, dos padrões de atos e relacionamentos sociais, e sobre o estatuto das explicações sociológicas (e das ciências sociais em geral). No primeiro caso, argumentando-se que as ordens sociais são inerentemente instáveis. No segundo, que as regularidades sociais têm um caráter historicamente situado que não permite explicações sociológicas com o formato de leis.

Vejamos, primeiro, a tese da instabilidade das ordens sociais. Afirmar que o conhecimento pode mudar o objeto do conhecimento não é o mesmo que afirmar que todo o conhecimento muda necessariamente o objeto do conhecimento. Uma vez mais estamos perante um processo social variável, podendo essa variação ser sociologicamente explicada.

A relação entre conhecimento e mudança depende, em especial, do tipo de objeto do conhecimento, nuns casos, ou do poder dos agentes capazes de atuar com base nesse conhecimento, noutros casos. O exemplo da profecia autorrealizável tratado por Merton permite ilustrar a primeira condição. A crise financeira de 2008-2009, a segunda.

A profecia autorrealizável é uma previsão que se concretiza por ser formulada em termos tais que suscita comportamentos que confirmam esses mesmos termos, independentemente da verdade inicial destes. É um caso particular de retroação positiva entre crença e comportamento. No célebre exemplo de Merton (1970 [1968]: 516-518), um banco saudável vai à falência em consequência da corrida aos depósitos originada pelo rumor de que esse banco estaria falido.

Pode este caso ser considerado como exemplo de uma dinâmica social geral? Não é necessária uma análise muito aprofundada para responder negativamente. De facto, o exemplo trata de um tipo específico de comportamento, baseado em expectativas, num contexto relacional caracterizado por fraca interação, a reação de pânico, e num quadro macrossocial de fraca regulação. Sem a reunião destas três condições, a profecia não teria condições para se concretizar.

Passando ao segundo exemplo. A crise financeira de 2008-2009 tornou evidente que o desenvolvimento do sistema financeiro internacional tinha sido caracterizado por um incremento da sua complexidade operativa, nomeadamente dos instrumentos de crédito, a par de uma simplificação dos mecanismos da sua regulação. Existe, hoje, uma abundante literatura nas ciências sociais e económicas que converge no sentido da tese segundo a qual a viabilização e estabilização 
da complexidade exigem simplificação operativa, nomeadamente por especialização das atividades, dos agentes e das organizações (diferenciação), a par de incrementos na coordenação das partes especializadas (integração). Este conhecimento, partilhado por cientistas sociais e decisores políticos, não alterou a realidade financeira, por razões triviais. O desenvolvimento do sistema financeiro internacional envolve interesses e assimetrias de poder que se interpõem entre conhecimento, ação e eficácia da ação. Neste caso, com a consequência de que é a inoperância do conhecimento, e não a sua eficácia, que está na origem da instabilidade da ordem.

Resumindo, as relações entre conhecimento e mudança são complexas e variáveis, constituindo um objeto da análise sociológica de pleno direito. Resta esclarecer se não se constituem, em simultâneo, em limitação ao estatuto das explicações sociológicas. Recorde-se o argumento: dado que no mundo social o conhecimento muda o que é conhecido, ou pode mudar o que é conhecido, as regularidades sociais têm um caráter historicamente situado, o que não permite explicações sociológicas com o formato de leis.

Este argumento deve ser qualificado com base em duas observações. Primeira, leis ou princípios gerais sobre o mundo social não deixam de o ser por a sua validade estar limitada a um contexto historicamente situado. Praticamente todas as leis económicas são deste tipo, pois são leis sobre dinâmicas económicas em contexto de mercado, instituição historicamente situada. Ou seja, o argumento só é (parcialmente) válido se com ele se quiser dizer que não é possível formular leis gerais sobre a vida humana em todas as épocas e espaços (e, neste sentido não qualificado por limites de qualquer tipo, o argumento é provavelmente verdadeiro em qualquer ramo do conhecimento).

Segunda, os limites históricos das regularidades dependem do grau de generalidade dessas mesmas regularidades. Afirmar, como Marx e Engels (1999 [1848]), que os conflitos de classe são universais e centrais em todas as sociedades é provavelmente falso, tanto quanto os registos históricos nos permitem garantir. Porém, terão já um âmbito praticamente universal os princípios propostos por Simmel (1999 [1908]) segundo os quais os conflitos coletivos têm funções integradoras porque reforçam, em cada uma das partes em oposição, os sentimentos de pertença, as procuras de liderança e coordenação e as auto e heteroimagens coletivas das partes. Ao contrário da primeira afirmação, sobre o conteúdo historicamente variável dos conflitos, a segunda é mais geral e abstrata, pois identifica propriedades formais dos conflitos que são independentes dos conteúdos desses mesmos conflitos em diferentes épocas e espaços.

Ou seja, o facto de as regularidades sociais terem um caráter historicamente situado tem menos a ver com o estatuto das explicações sociológicas e mais com o rigor e o formato dessas explicações. Em termos de rigor, tal significa que as explicações sociológicas deverão incluir sempre a especificação do seu campo de validade. Em termos de formato, significa que esse campo de validade poderá ser mais ou menos alargado em função do nível de abstração da explicação. O que significa ainda que, neste domínio, o problema da relação entre conhecimento e mudança, mais do que enfraquecer o caráter ordenado do mundo social e, consequentemente, 
afetar o tipo de explicação que sobre ele é possível construir, tem sobretudo consequências metodológicas.

Resta uma última questão. Se o conhecimento afeta o objeto de conhecimento, os princípios gerais de explicação sociológica não caducam no próprio momento em que são formulados, por deixarem a partir daí de ser válidos (por transformação do objeto a que se referem)? A resposta é não, ou melhor, não enquanto afirmação geral. Há conhecimento que afeta o objeto e há conhecimento que não o afeta. Por exemplo, as dinâmicas de conflito não se alteram porque conhecemos as explicações de Simmel sobre elas. Ou, como lembra Turner (1991: 539), o princípio geral segundo o qual a desrotinização do quotidiano dos agentes humanos produz insegurança vivida como ansiedade (Giddens, 1984: 50-61) não deixa de ter efeitos de insegurança vividos como ansiedade só porque foi formulado e os agentes o conhecem. Tal como no caso da previsibilidade, os efeitos de dupla hermenêutica deveriam ser tratados como variáveis e transformados em objeto de análise sociológica.

Neste contexto, merece ainda nota particular uma modalidade específica de transformação do objeto em consequência do conhecimento sobre ele produzido: a utilização de conhecimento sociológico no desenvolvimento de políticas públicas. Nas sociedades modernas, o conhecimento sociológico, e das ciências sociais e económicas em geral, é usado para, intencionalmente, produzir mudanças, em particular no plano institucional. Há hoje arranjos institucionais que foram desenhados para terem as funções que têm e cuja conceção mobilizou conhecimento pericial de natureza científica.

Esta modalidade de relação entre conhecimento e objeto do conhecimento suscita duas observações. Primeira, em lugar de produzir instabilidade das ordens sociais, a utilização de conhecimento pericial de natureza científica em políticas públicas de desenho institucional pode contribuir para o reforço dessas mesmas ordens, ainda que em novas bases. Segunda, a utilização pública da sociologia, em lugar de criar instabilidade nos enunciados sociológicos, isto é, de eliminar as condições da sua validade por alteração do objeto a que dizem respeito, confirma a plausibilidade desses enunciados por via da sua eficácia técnica.

Resumindo os argumentos desta secção:

a) afirmar que o conhecimento pode mudar o objeto do conhecimento não é o mesmo que afirmar que todo o conhecimento muda o objeto do conhecimento;

b) as relações entre conhecimento e mudança são variáveis e constituem objeto da análise sociológica;

c) leis ou princípios gerais sobre o mundo social não deixam de o ser por a sua validade estar limitada a um contexto historicamente situado;

d) o campo de validade das leis ou princípios gerais sobre o mundo social é tanto mais amplo quanto mais elevado for o seu nível de abstração.

Em conclusão, a reflexividade dos agentes humanos não se opõe lógica ou empiricamente à constituição da ordem social, antes constitui um elemento desta, nem limita, embora condicione, os enunciados explicativos que sobre ela podem ser construídos. 


\section{Ordem social como ordem relacional factual}

Resta precisar um pouco mais o que se entende por ordem social. Num sentido estritamente sociológico, a ordem pode ser definida em termos factuais como "a antítese de [...] aleatoriedade ou acaso" (Parsons, 1937: 91), o oposto de caos, como padronização, sem qualquer pressuposto sobre o grau e estabilidade dessa padronização ou o modo como ela é alcançada. A ordem social concretiza-se em padrões de relações sociais. Esses padrões são observáveis em múltiplos domínios e a diferentes escalas, nas similitudes dos comportamentos individuais como nas regularidades dos encontros entre agentes humanos, na formação de grupos e organizações como no funcionamento das instituições e na distribuição dos recursos sociais.

Aparentemente simples e evidente, a expressão "relações sociais" tem, pois, um amplo campo de aplicação: "relações entre indivíduos (e grupos) e [...] relações entre essas relações (e entre tais relações e [...] os produtos dessas relações)" (Bhaskar, 1989 [1979]: 28-29). Ou seja, falamos de relações sociais, indiferentemente, a propósito de relações entre pessoas, entre grupos ou entre organizações, ou ainda de relações entre instituições ou entre categorias sociais. Note-se que, ao identificarmos estes vários campos de aplicação da expressão, estamos já a identificar padrões, isto é, dimensões da ordem social. Grupos, organizações, categorias sociais ou instituições são padrões sociais, são conjuntos de relações relativamente estáveis e com formas reconhecíveis. Por isso os podemos distinguir entre si. Não são sempre, porém, apenas relações entre pessoas, e isso tem consequências.

As relações entre pessoas são relações de interação. São relações ordenadas em particular pelo uso de recursos e regras de comunicação partilhados ou por fórmulas estereotipadas de comportamento que permitem combinar atos. Observamos essa ordenação nos modos visíveis e previsíveis de comunicação verbal e gestual entre pessoas que se encontram. Para um extraterrestre acabado de chegar ao nosso planeta, sem conhecer qualquer língua humana, a manifestação mais imediatamente observável da ordem social seria provavelmente a ordem da interação, isto é, o uso sistemático, repetido, de reportórios de falas, gestos e vestuários nos encontros entre pessoas.

As relações entre grupos são relações entre conjuntos de pessoas, e falar de conjuntos de pessoas é o mesmo que falar de relações entre pessoas. Ou seja, relações entre grupos são relações entre relações entre pessoas, pois cada grupo é já um conjunto particular de relações entre pessoas. A distinção não é formalista, porque relações entre pessoas e relações entre relações, como sejam as relações entre grupos, não têm as mesmas propriedades. Muitos dos equívocos que prejudicam o trabalho sociológico resultam do esquecimento desta distinção básica.

Na maior parte das situações, as relações entre grupos não são relações entre todos os membros de um grupo com todos os membros de outro grupo. São, em regra, relações entre representantes de cada grupo. A representação de cada grupoé, por sua vez, o resultado de processos que envolvem relações entre pessoas no âmbito de cada grupo, os quais passam, em particular, pela delegação num ou mais membros do grupo da função de representação do conjunto do grupo, bem como pela negociação do conteúdo dessa representação. Duas notas sobre estas dinâmicas. 
Primeira, alguns padrões sociais podem ser explicados como o resultado emergente de processos relacionais de agrupamento, no exemplo, os processos de representação, de delegação ou de negociação que constituem o grupo internamente e permitem a sua relação com outros grupos, a qual, quando continuada, reforça o reconhecimento externo do grupo. Cada um daqueles processos envolve relações entre pessoas. Mas, no final, a relação entre grupos é uma relação entre conjuntos de relações entre pessoas (os grupos) através de relações entre pessoas (os representantes).

Segunda, as relações entre os membros dos grupos e entre os grupos têm propriedades diferentes. No primeiro caso podemos, por exemplo, explicar as propostas de cada membro do grupo pelos seus interesses ou orientações, em resumo, pelas suas razões subjetivas. O mesmo não é suficiente quando queremos explicar as propostas do grupo expressas pelos seus representantes e negociadas entre os seus membros. A negociação entre os membros, e não apenas as razões de cada membro, explica o conteúdo daquelas propostas coletivas. A subjetividade das razões é, pois, uma propriedade específica das pessoas e das relações entre pessoas, não dos grupos e das relações entre grupos. Do mesmo modo, a representação por delegação é uma propriedade dos grupos e da relação entre grupos, não das pessoas.

O funcionamento coletivo dos grupos tende a ser relativamente precário, nomeadamente quando estes crescem em número de participantes e não são de filiação compulsiva e exclusivista. A precariedade resulta do caráter aberto da negociação e da delegação enquanto processos de constituição da coordenação e representação do grupo. Os agrupamentos hierárquicos superam essa precariedade fixando e estabilizando a coordenação e a representação através da criação de regras formais, de mecanismos de controlo e de estruturas de decisão que, em conjunto, permitem uma maior divisão do trabalho. Constituem-se, desta forma, em organizações.

Tanto as relações entre pessoas como as relações entre agrupamentos de pessoas são relações entre atos, individuais no primeiro caso, coletivos no segundo. Por isso, podemos falar em cooperação ou em conflito tanto entre pessoas como entre grupos, incluindo organizações. Noutros casos, porém, o uso da expressão relações sociais não remete para relações entre pessoas ou agrupamentos de pessoas e, portanto, para atos. Por exemplo, quando se fala nas relações entre trabalho e família, fala-se das relações entre as regras do trabalho e as regras da família, não entre pessoas ou conjuntos de pessoas. Mais concretamente, fala-se de relações entre propriedades das relações entre pessoas (ou de relações entre relações).

Assim, quando se diz que as relações entre pais e filhos envolvem afetividade, faz-se referência a uma propriedade que caracteriza (ou se entende que deverá caracterizar) as relações entre pais e filhos. O mesmo acontece quando, por oposição, se diz que as relações profissionais são (ou se entende que devem ser) afetivamente neutras. Num caso como noutro, as relações assim definidas constituem aquilo a que se chama papéis. Papéis são definições padronizadas de comportamentos na relação com outros em domínios específicos de atividade. Relações de papéis não são pois relações entre pessoas em concreto, mas relações entre pessoas no desempenho de uma atividade relacional específica. Nas sociedades modernas, 
uma mesma pessoa desempenha diversos papéis, consoante a relação em que se encontra. Por exemplo, papel de dirigente na relação hierárquica com os subordinados na esfera profissional e papel de pai na relação pai-filho na esfera familiar.

As relações entre papéis são relações entre as propriedades das relações que constituem cada papel. Assim, quando se diz que família e trabalho não devem ser confundidos, diz-se que não se espera, por exemplo, que a afetividade das relações entre pais e filhos se prolongue para a esfera profissional, nem que a neutralidade afetiva das relações profissionais invada a esfera familiar. Ou seja, reconhece-se que as relações entre família e profissão incluem incompatibilidades.

Exemplificando, não será difícil imaginar uma situação em que uma mesma pessoa seja objeto de pressões contraditórias para, enquanto profissional, cumprir deveres de isenção e não privilegiar o filho no acesso ao emprego e, enquanto pai, cumprir deveres de proteção e privilegiar o filho no acesso ao emprego. Esta relação de incompatibilidade é uma relação entre propriedades opostas de duas relações de papel (antes de ser, eventualmente, um dilema para quem a experimenta).

A existência de relações de compatibilidade ou incompatibilidade entre papéis resulta das interdependências entre esses mesmos papéis, constitutivas do que chamamos instituições. As interdependências entre propriedades das relações sociais têm um caráter sistémico, ordenando porque colocam limites às possibilidades de combinação estável dessas mesmas propriedades.

Nem todas as propriedades das relações sociais são normativamente formuladas como os papéis. Por exemplo, o acesso desigual aos recursos sociais começa por ser uma propriedade de facto dos lugares sociais pelos quais as pessoas estão distribuídas antes de estas poderem sequer agir, ou seja, por herança (pelo menos num primeiro momento). As interdependências sistémicas entre lugares sociais desiguais ordenam por padronização das oportunidades dos seus ocupantes, não por especificação dos seus comportamentos.

Lugares com propriedades semelhantes no domínio das desigualdades reúnem pessoas com oportunidades semelhantes e, portanto, com maior probabilidade de terem comportamentos individuais semelhantes e interesse em agir em conjunto. Constituem-se, assim, categorias de pessoas, nomeadamente classes, definidas não em termos absolutos mas no espaço relacional a que chamamos hierarquias de estratificação.

Em síntese, a expressão "relações sociais" recobre diferentes tipos de fenómenos sociais:

a) relações de interação entre pessoas;

b) relações entre relações entre pessoas, por exemplo, relações entre agrupamentos de pessoas, incluindo organizações;

c) relações entre propriedades das relações entre pessoas, por exemplo, relações entre papéis ou entre lugares sociais.

Diferentes tipos de fenómenos sociais têm propriedades distintas. As relações entre pessoas são relações intersubjetivas e relações entre atos. As relações entre agrupamentos de pessoas são relações entre atos, ou seja, relações de cooperação ou 
conflito, de troca ou competição, mas não são relações intersubjetivas. As relações entre propriedades das relações entre pessoas podem ser de compatibilidade ou incompatibilidade, de consistência ou inconsistência, de equilíbrio ou tensão, mas não são, exceto em termos metafóricos que devem ser evitados na análise sociológica, relações entre atos, ou seja, relações de cooperação ou conflito, de troca ou competição. E não são também, muito menos, relações de intersubjetividade.

Esta especificação preliminar (e parcial) dos diferentes domínios e propriedades das relações sociais permite afinar a definição de ordem social e preparar o terreno para a sua análise e explicação. Ordem social é, no sentido factual aqui usado, e numa definição preliminar, a padronização que emerge dos processos relacionais de interação, de agrupamento e de interdependência sistémica.

A interação ordena ao combinar atos. A constituição de grupos ordena porque sustenta a coordenação e estabilização de atos interativamente combinados, em particular por processos de hierarquização das relações. A interdependência sistémica ordena pela combinação de propriedades de diferentes relações sociais. A combinação vertical destes três "níveis de integração das relações sociais" (Costa, 1999: 490) constitui as sociedades através de processos de ordenação das interações a escalas de crescente amplitude, ou seja, suporta o alongamento das relações sociais no espaço e no tempo.

\section{Referências bibliográficas}

Alexander, Jeffrey C. (1987), Sociological Theory Since 1945, Londres, Hutchinson.

Bhaskar, Roy (1989 [1979]), The Possibility of Naturalism, Londres, Harvester Wheatsheaf (2. '⿳亠口冋 edição).

Burns, Tom R., e Thomas Dietz (1992), “Cultural evolution: social rule systems, selection and human agency", International Sociology, 7 (3), pp. 259-283.

Costa, António Firmino da (1999), Sociedade de Bairro. Dinâmicas Sociais da Identidade Cultural, Oeiras, Celta Editora.

Giddens, Anthony (1984), The Constitution of Society. Outline of the Theory of Structuration, Cambridge, Polity Press.

Giddens, Anthony (1992 [1989]), As Consequências da Modernidade, Oeiras, Celta Editora.

Marx, Karl, e Friedrich Engels (1999 [1848]), Manifesto do Partido Comunista, Lisboa, Edições Avante.

Merton, Robert K. (1970 [1968]), Sociologia. Teoria e Estrutura, São Paulo, Editora Mestre Jou.

Parsons, Talcott (1937), The Structure of Social Action, Nova Iorque, McGraw-Hill.

Pires, Rui Pena (2007), “Árvores conceptuais: uma reconstrução multidimensional dos conceitos de acção e de estrutura", Sociologia, Problemas e Práticas, 53, pp. 11-50.

Simmel, Georg (1999 [1908]), Sociologie. Études sur les Formes de la Socialisation, Paris, PUF.

Turner, Jonathan H. (1991), The Structure of Sociological Theory, Belmont, CA, Wadsworth Publishing Company (5. ㄹ edição).

Wallace, Walter L. (1983), Principles of Scientific Sociology, Nova Iorque, Aldine Publishing Company. 
Wrong, Dennis H. (1994), The Problem of Order. What Unites and Divides Society, Nova Iorque, The Free Press.

Rui Pena Pires. Professor no Departamento de Sociologia do Instituto Universitário de Lisboa (ISCTE-IUL) e investigador no CIES-IUL, Lisboa.

E-mail: rpenapires@iscte.pt

\section{Resumo/ abstract/ résumé/ resumen}

\section{O problema da ordem}

Como se explica a emergência de padrões ordenados de atos e relacionamentos protagonizados por indivíduos autónomos, criativos e livres? Que consequências têm sobre esses mesmos indivíduos aqueles padrões de atos e relacionamentos? Estas questões integram o que podemos designar como o "problema da ordem". Neste artigo, contesta-se a associação entre aquele problema e as ideias de reprodução, consenso e determinismo, argumenta-se que a previsibilidade da vida social é maior do que muitas vezes reconhecido e sustenta-se que a reflexividade dos agentes humanos não se opõe lógica ou empiricamente à emergência de regularidades sociais. Por fim, define-se ordem social em termos factuais como a padronização que emerge dos processos relacionais de interação, de agrupamento e de interdependência sistémica.

Palavras-chave ordem social, previsibilidade, reflexividade, relações sociais.

\section{The problem of order}

How do you explain the emergence of ordered patterns of relationships and acts perpetrated by autonomous, creative and free individuals? What impacts have on those same individuals these patterns of acts and relationships? These issues are what we designate as the "problem of order". This article challenges the association between this problem and the ideas of reproduction, consensus and determinism, argues that the predictability of social life is greater than often recognized and that reflexivity of human agents does not preclude logically or empirically the emergence of social regularities. Finally, we define the social order as a factual matter that emerges as the standardization of relational processes of interaction, grouping and systemic interdependence.

$\underline{\text { Keywords }}$ social order, predictability, reflexivity, social relations. 
Le problème de l'ordre

Comment expliquer l'émergence d'ensembles ordonnés de relations et d'actes produits par des individus autonomes, créatifs et libres? Quel impact ont ces mêmes ensembles ordonnés de relations et d'actes sur les individus? Ces questions constituent ce que nous désignons comme le "problème de l'ordre". En cet article on remet en question le lien entre ce problème et les idées de reproduction, consensus et déterminisme, il est soutenu que la prévisibilité de la vie sociale est plus grande qu'on ne le pense et que la réflexivité des agents ne fait pas obstacle logiquement ou empiriquement à l'émergence de régularités sociales. Enfin, nous définissons l'ordre social comme une question de fait qui émerge comme la standardisation des processus relationnels d'nteraction, de regroupement et d'interdépendance systémique.

$\underline{\text { Mots-clés }}$ ordre social, prévisibilité, réflexivité, relations sociales.

\section{El problema del orden}

¿Cómo se explica la aparición de patrones ordenados de relaciones y actos perpetrados por individuos autónomos, creativos y libres? ¿Qué impacto tienen en esos mismos individuos estos patrones de relaciones y actos? Estas cuestiones impregnan lo que designamos como el "problema del orden". Este artículo cuestiona la asociación entre este problema y las ideas de la reproducción, el consenso y el determinismo, argumenta que la previsibilidad de la vida social es mayor que se reconoce a menudo, y argumenta que la reflexividad de los agentes humanos no se opone lógica o empíricamente a la emergencia de regularidades sociales. Por último, se define el orden social como cuestión de hecho, como la estandarización de los procesos relacionales de la interacción, la agrupación y la interdependencia sistémica.

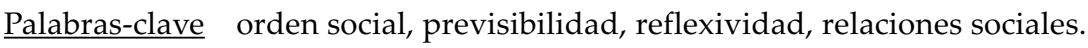

